\title{
A Dynamic Knowledge Model of Project Time-Cost Analysis Based on Trend Modelling
}

\author{
Karel Doubravský1, Radek Doskočil ${ }^{1 *}$, Mirko Dohnal² \\ 1 Department of Informatics, Faculty of Business and Management, Brno University of Technology, \\ Kolejní 2906/4, 61200 Brno, Czech Republic \\ 2 Department of Economics, Faculty of Business and Management, Brno University of Technology, \\ Kolejní 2906/4, 61200 Brno, Czech Republic \\ *Corresponding author, e-mail: doskocil@fbm.vutbr.cz
}

Received: 16 October 2018, Accepted: 13 March 2019, Published online: 11 December 2019

\begin{abstract}
This paper investigates the application of trend quantifiers of project time-cost analysis as a tool for decision-making support in the project management. Practical project management-related problems are solved under information shortages. It means that methods of statistical analysis cannot be easily used as they are based on the law of large numbers of observations. Numbers are information intensive quantifiers. The least information intensive quantifier is a trend; its values are increasing, constant, decreasing. If a derivative cannot be quantified by a trend, then nothing is known and therefore nothing can be analyzed/predicted. For this reason, the trend model $\mathrm{M}$ was created. The model $\mathrm{M}$ is based on a degraded set of differential equations or heuristics. $\mathrm{A}$ trend analysis of the model $\mathrm{M}$ is an evaluation of the relevant discrete set of solutions/scenarios S. A trend reconstruction is an evaluation of the model M if a (sub) set of scenarios $\mathrm{S}$ is given. The paper studies linear reconstruction, i.e. the model $\mathrm{M}$ is a set of linear differential equations. The trend reconstruction is partially reverse process to trend analysis. A case study has 7 variables (e.g. Project duration, Direct personnel costs, Indirect personal costs etc.) and the reconstructed set of linear differential equations has 7 equations. The set of 243 scenarios is obtained if this reconstructed set of trend linear equations is solved. Any future or past behavior of the model $\mathrm{M}$ can be described by a sequence of obtained scenarios.
\end{abstract}

\section{Keywords}

project management, trend models, linear differential equations, linear reconstruction

\section{Introduction}

Knowledge is the cornerstone of project management in every project life cycle. Project management is a complex process whose success depends on many factors (Jugdev and Müller, 2005; Serrador and Pinto, 2015). Metrics such as the scope, costs, purpose of a project or customer satisfaction are usually considered as the criteria for project success (Joslin and Müller, 2015).

An important phase of project management is the cost analysis of a project. Many studies have analysed identif the relationship between knowledge, time and cost as factors in the success of a project. Time, cost, and quality are three important factors which tend to be in conflict.

The time estimates for the activities of a project are based on the number of resources that will be assigned to each project activity. Resources may be added to selected activities to reduce the project completion time.
Adding resources generally increases project costs, and thus decision-making to reduce activity times must take into consideration the additional project cost involved.

Kelley (1961) introduces the mathematical basis of the Critical-Path Method (CPM) as a new technique for planning and coordinating complex project tasks. This technique is based on a mathematical model that involves information about the sequence, duration and cost of each component of a project. This special parametric linear program may be solved efficiently by network flow methods. Analysis of the solutions enables operating personnel to answer questions relating to budgetary requirements, procurement and design limitations and the effects of delays.

Klafszky and Hajdu (1993) a new approach to the timecost trade off problem (CPM/cost). Their solution is based on the theory of network flows and makes use of 
the duality theorem of linear programming. The solution is simpler and easy to program. The speed of the solution depends on the speed of the algorithm used to solve the maximal flow problem.

The basic hypothesis in the original CPM/COST technique is that a typical duration and a normal cost can be determined for the typical duration of each and every activity (Kelley and Walker, 1959). Problems may arise in relation to the graphical display of the network and poor modelling when describing logical relationships between activities. To address these limitations a new technique, Precedence Diagramming Method (PDM) was developed. The PDM technique gives more flexibility in modelling by introducing minimal and maximal precedence relationships (Hajdu, 2013; Mályusz and Hajdu, 2009).

A project environment is a very flexible system. The basic project variables - costs and resources - change in relation to the time available (Koltai and Tamássy, 1997). It is necessary to use dynamic modelling to describe these dynamic processes (Vanhoucke, 2013). Several authors have applied dynamic modelling to project management.

Wu et al. (2007) present a computer-based training module (CBT) for student education in software project management. The simulation component of the CBT module is implemented using system dynamics simulation modeling.

Šviráková (2014) presents a new approach to teaching project managers in the creative industries. The proposed model is based on system dynamics modelling employing PRINCE2 methodology and using the principles of the EVM (Earned Value Management) method. The project plan is proposed as a system dynamic model. Project managers can compare the actual results achieved with the prior expectations.

Song et al. (2015) devised a system dynamic model that includes the dynamic adjustment mechanism of resource allocation to improve the dynamic capabilities of Projectbased organizations (PBO). The model comprises three components of dynamic capabilities: adaptive capability, absorptive capability, innovative capability. The model reflects dynamic capabilities in $\mathrm{PBO}$ and serves as a tool for knowledge sharing in knowledge management. Knowledge sharing has effects on dynamic capabilities during the lifecycle of PBO when the external environment changes from a moderate to a high velocity dynamic.

The key requirement of all the above-mentioned methods is the definition of input data, such as normal time, normal cost, etc. Relevant and high quality input information plays a key role in the success of projects. The key problem of nearly all new realistic project models is a serious shortage of information (Dohnal and Doubravsky, 2016; Doskočil and Doubravsky, 2017) and problems related to quantifying/ measuring some of the variables such as competence and complexity, (Bosurgi et al., 2017; de Villiers et al., 2016). If there is a clear shortage of information only qualitative results can be obtained. However, qualitative analysis can be very useful if further conventional statistical analysis is feasible and interesting. Objective and subjective methods must be synthesized to derive the obvious benefits of objective precision and semi-subjective common-sense abilities.

The main research goal of this paper is to present a new approach to support decision-making in project management when there is a shortage of information. The proposed approach is not a direct substitute for traditional methods such as CPM/COST, but is intended to facilitate time-cost analysis in the initialization and planning phase. Concrete numerical inputs about time durations and costs of project activities are not possible in this phase.

\section{Material and methods}

Previously described models which are used to study different knowledge-based model of a project time-cost analysis are based on deep knowledge information.

Deep knowledge items are laws which reflect the undisputed elements of the corresponding theory. For example, the law of gravity is an example of a deep knowledge item. The law of gravity has no exceptions. This is a typical feature of any deep knowledge item.

However, nearly all new realistic project issues are only very rarely based on deep knowledge items. A shallow knowledge item is usually a heuristic or a result of a statistical analysis of observations and typically there are (many) exceptions (Orrell and Fernandez, 2010; Orrell and McSharry, 2009).

Many shallow knowledge items are only available as verbal descriptions based on trends which may be decreasing, constant or increasing (Yan et al., 2013). For example, if marketing-related investments are increasing then business profits are increasing. Pairwise trend relations are a graphical representation of the verbal descriptions. Typical examples of pairwise trend relations are given in Fig. 1.

All the pairwise relations between $X$ and $Y$ in the graphs Fig. 1 are trend relations. This means that nothing is numerically quantified. For example, relation No. 23 indicates that

- While the relation is increasing the first derivative $\mathrm{d} Y / \mathrm{d} X$ is positive.

- There is a "saturated" relationship between $Y$ and $X$, the second derivative is therefore negative; it means that there is a quantitatively unknown upper limit. 

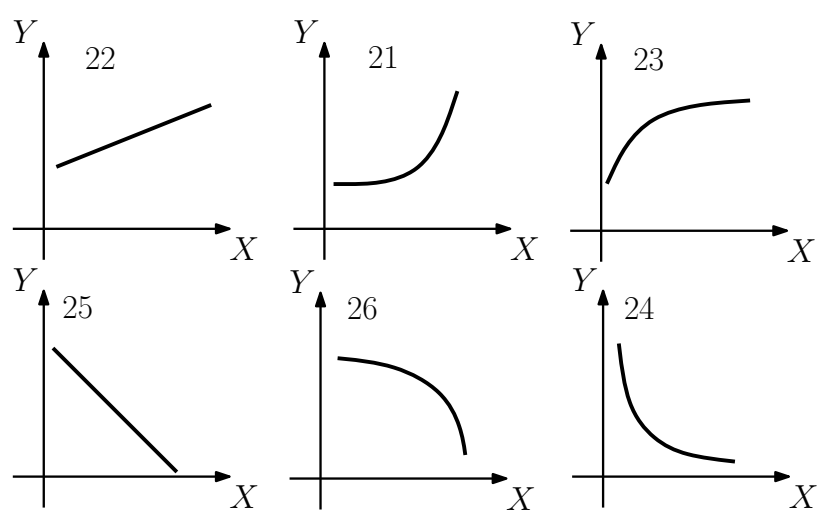

Fig. 1 Examples of pairwise trend relations (Dohnal, 1991)

The variables $X$ and $Y$ are simply replaced by those variables which are studied as elements of a trend model. Numbers 21, 22, 23, 24, 25 and 26 are merely indicators of the pairwise trend relations for the first quadrant of a coordinate system (Dohnal, 1991).

A new type of information non-intensive quantifier requires new algorithms for relevant model $\mathrm{M}$ analysis and interpretation of results. The basic relevant definitions follow.

\subsection{Trend analysis}

The trend analysis of the trend model M, see Eq. (1), is based on four values, see Table 1.

$\mathrm{M}\left(X_{1}, X_{2}, \ldots, X_{n}\right)$

The trend model M Eq. (1) is specified when all the monitored variables $X_{1}, X_{2}, \ldots, X_{n}$ are described by triplets

$$
\left(X_{i}, \mathrm{D} X_{i}, \mathrm{DD} X_{i}\right) \text {, }
$$

where $i=1,2, \ldots, n, \mathrm{D} X$ is the first qualitative time derivative of $X$ and $\mathrm{DD} X$ is the second qualitative time derivative of the variable $X$.

For example, the triplet is $(+,+,+)$, abbreviated to $(+++)$. This triplet can be interpreted so that the variable $X$ is positive $(X=(+))$, growing in time $(\mathrm{D} X=(+))$ and growth accelerates $(\mathrm{DD} X=(+))$.

The trend model $\mathrm{M}$ can be represented by a set of differential equations (Vicha and Dohnal, 2008). When the model Eq. (1). is solved the set of $n$-dimensional scenarios is obtained $S(n, m)$. The $m$ scenarios are:

$$
\begin{aligned}
& \mathrm{S}(n, m)= \\
& \left\{\left[\left(X_{1}, \mathrm{D} X_{1}, \mathrm{DD} X_{1}\right),\left(X_{2}, \mathrm{D} X_{2}, \mathrm{DD} X_{2}\right), \ldots,\left(X_{n}, \mathrm{D} X_{n}, \mathrm{DD} X_{n}\right)\right]_{j}\right\},
\end{aligned}
$$

Table 1 The quantifiers, see e.g. (Vicha and Dohnal, 2008)

\begin{tabular}{lcccc}
\hline Values: & Positive & Zero & Negative & Anything \\
\hline Trend: & Increasing & Constant & Decreasing & $\begin{array}{c}\text { Any } \\
\text { direction }\end{array}$ \\
Symbol: & + & 0 & - & $*$ \\
\hline
\end{tabular}

Realistic qualitative models can involve hundreds of scenarios (Doubravsky and Dohnal, 2018).

The qualitative shallow model, studied in this paper, is a set of w pairwise relations, see Fig. 1:

$P_{v}\left(X_{i}, X_{j}\right), v=1,2, \ldots, w$.

This set of relations can be solved to evaluate all the scenarios Eq. (3) which satisfy the model Eq. (4). This paper does not study algorithms which are used to create trend models - see Dohnal, (1991) and Vicha and Dohnal, (2008) for further details.

For example, the following three-dimensional scenario, $n=3$,

$$
\begin{array}{ccc}
X_{1} & X_{2} & X_{3} \\
(+++) & (+-0) & (+--)
\end{array}
$$

indicates that $X_{1}$ is increasing more and more rapidly, while $X_{2}$ decreases linearly, and $X_{3}$ is decreasing more and more rapidly.

It is possible to introduce higher trend derivatives, e.g. the third derivative $X_{n}$. However, knowledge of complex variables is usually so poor that this is rarely possible (Bredeweg et al., 2016).

For example, the following model is studied

$\begin{array}{llcc} & \text { Shape } & X & Y \\ 1 & 21 \text { (see Fig. 1) } & X_{1} & X_{2}, \\ 2 & 25 \text { (see Fig. 2) } & X_{3} & X_{2} .\end{array}$

The model Eq. (5) is solved and 13 three-dimensional scenarios are obtained, see Table 2.

\subsection{Transitional graph}

A complete set of all possible one-dimensional transitions is given in Table 3 .

The third line of Table 3 indicates that it is possible to transfer the triplet $(++-)$ into the triplet $(+0-)$. Table 3 is not meant to be followed as a dogma, however (Dohnal, 1991). It could be modified on an ad hoc basis.

A transitional graph $\mathrm{G}$ is the directed graph. Its nodes are the set of scenarios $\mathrm{S}$ and $\mathrm{T} \subseteq(\mathrm{S} \times \mathrm{S})$ is the set of the ordered pairs (the transitions).

$\mathrm{G}=(\mathrm{S}, \mathrm{T})$

where $j=1,2, \ldots, m$. 
Table 2 Scenarios

\begin{tabular}{llll}
\hline & $X_{1}$ & $X_{2}$ & $X_{3}$ \\
\hline 1 & +++ & +++ & +-- \\
2 & ++0 & +++ & +-- \\
3 & ++- & +++ & +-- \\
4 & ++- & ++0 & +-0 \\
5 & ++- & ++- & +-+ \\
6 & $+0-$ & $+0-$ & $+0+$ \\
7 & +00 & +00 & +00 \\
8 & $+0+$ & $+0+$ & $+0-$ \\
9 & +-+ & +-+ & ++- \\
10 & +-0 & +-+ & ++- \\
11 & +-- & +-+ & ++- \\
12 & +-- & +-0 & ++0 \\
13 & +-- & +-- & +++ \\
\hline
\end{tabular}

Table 3 A list of all one-dimensional transitions

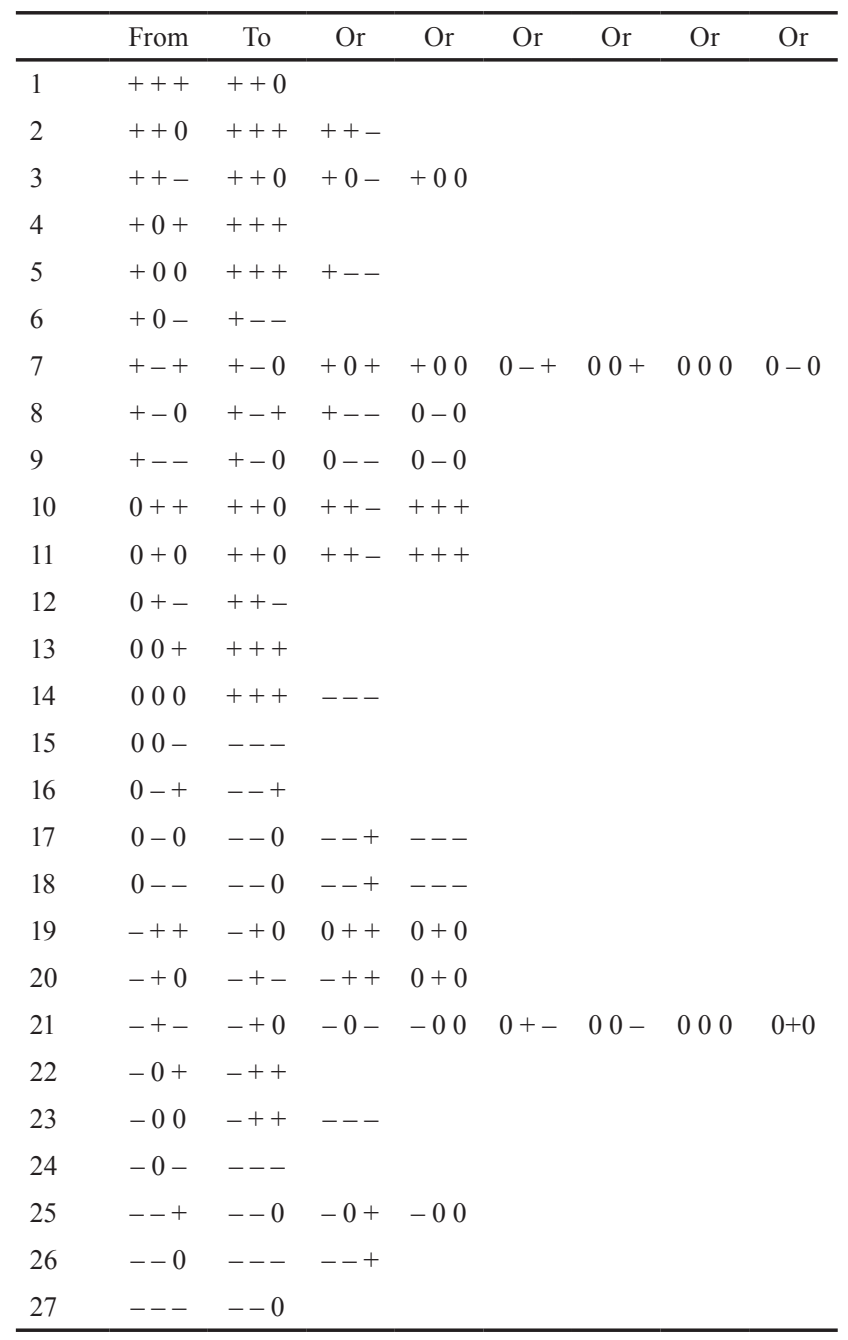

Elements of the set $\mathrm{T}$ are the transitions between scenarios $\mathrm{S}$ based on Table 3 .

The set of $n$-dimensional transitions $\mathrm{T}$ can easily be generated by the corresponding set of scenarios $\mathrm{S}$ using
Table 3. All $n$ one-dimensional transitions must satisfy Table 3 if $n$-dimensional scenarios are studied.

For example, Fig. 2 represents a transitional graph $\mathrm{G}$ of scenarios from Table 2 while respecting transitions of Table 3.

Any path is a trend description of a forecast or a history. A transitional graph thus represents all possible future/past behaviors of the model. Therefore, any forecast is identical to a choice of a path through the transitional graph.

Pairwise relationships are based on experiences and observations of project team members and therefore pairwise relations do not need to describe all the relations of monitored variables.

Trend reconstruction allows additional relationships to be found between monitored variables.

\subsection{Trend reconstruction}

Let us suppose that a set of available scenarios is $\mathrm{S}_{\mathrm{M}}$. The complete set of scenarios $\mathrm{S}$ is unknown:

$\mathrm{S} \supseteq \mathrm{S}_{\mathrm{M}}$.

The result of an analysis of trend model $\mathrm{M}$ is the set of scenarios S Eq. (3):

$\mathrm{M} \rightarrow \mathrm{S}_{\mathrm{M}}$.

A trend reconstruction is the reverse process to the trend analysis Eq. (8). Model $\mathrm{M}_{\mathrm{S}}$ is reconstructed taking into consideration a given set of scenarios $\mathrm{S}_{\mathrm{M}}$

$\mathrm{S}_{\mathrm{M}} \rightarrow \mathrm{M}_{\mathrm{S}}$

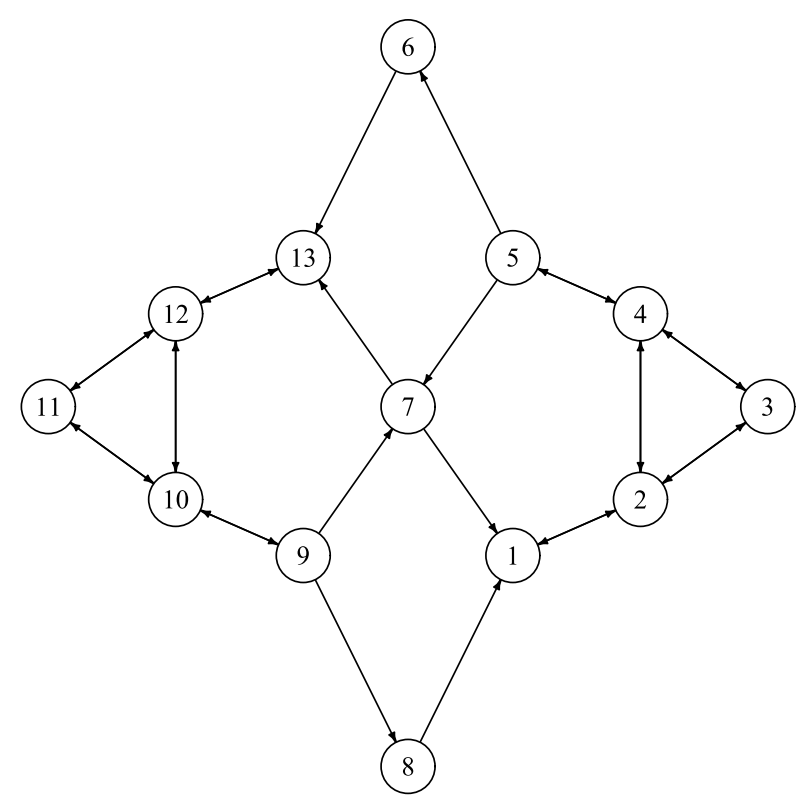

Fig. 2 Transitional graph $\mathrm{G}$ 
If the reconstructed model $\mathrm{M}_{\mathrm{S}}$ is analyzed then the resulting set of scenarios is $\mathrm{S}_{\mathrm{MS}}$

$\mathrm{M}_{\mathrm{S}} \rightarrow \mathrm{S}_{\mathrm{MS}}$

which is a superset of $\mathrm{S}_{\mathrm{M}}$

$\mathrm{S}_{\mathrm{MS}} \supseteq \mathrm{S}_{\mathrm{M}}$

An assumption concerning linearity must be made. A general nonlinear synthesis is based on the testing of all scenarios. Each scenario is either accepted or rejected. This brutal force approach requires an enormous amount of computer time and is not applicable if the number of variables is high (Dincbas et al., 1990; Harrington and SalibiánBarrera, 2010; Singhi et al., 1996). Therefore, a linear reconstruction is studied in this paper.

The following set of $t$ linear differential $n$-dimensional equations of $r$-th order is studied:

$\sum_{i=1}^{n} C_{i s} X_{i}+\sum_{i=1}^{n} \sum_{j=1}^{r} K_{i j s} D_{i j}=O_{s}$

where $s=1,2, \ldots, t ; C, K$ and $O$ are the set of qualitative constants, see Table $1, D_{i j}$ is a $j$-th derivative of an $i$-th variable $X_{i}$.

The set of linear equations Eq. (12) $\mathrm{M}_{\mathrm{SL}}$ is solved and the set of scenarios $\mathrm{S}_{\mathrm{ML}}$ is obtained. There is a strong analogy between Eq. (11) and the following linear version:

$\mathrm{S}_{\mathrm{ML}} \supseteq \mathrm{S}_{\mathrm{M}}$

The linear qualitative reconstruction is the reverse process to the trend analysis given in (Dohnal and Doubravsky, 2015; Doubravsky and Dohnal, 2018). The trend analysis is the procedure to finding a solution of the trend model. For the trend reconstruction the model is $\mathrm{S}_{\mathrm{M}}$ and the solution is the reconstructed model $\mathrm{M}_{\mathrm{SL}}$.

The solution $\mathrm{M}_{\mathrm{SL}}$ is a set containing triplets that meet all equations of the model $\mathrm{S}_{\mathrm{M}}$. The trend analysis is based on the qualitative sum + and product $\bullet($ Dohnal, 1991). The definitions of these operations are given in Table 4 and Table 5.

In Table 4 and Table 5 symbols $(+),(-),(0)$ represent values of a qualitative variable (the quantifiers, see Table 1). These values of the qualitative variable $X$ can be determined using the sign function of the variable $x$ and its derivations

$X=\left\{\begin{array}{l}(+) ; x>0, \\ (0) ; x=0, \\ (-) ; x<0 .\end{array}\right.$

The D $X$ and DD $X$ values of the variable $X$ can be determined analogously.
Table 4 Qualitative sum

\begin{tabular}{cccc}
\hline+ & $(+)$ & $(0)$ & $(-)$ \\
\hline$(+)$ & $(+)$ & $(+)$ & $(*)$ \\
$(0)$ & $(+)$ & $(0)$ & $(-)$ \\
$(-)$ & $(*)$ & $(-)$ & $(-)$ \\
\hline
\end{tabular}

Table 5 Qualitative product

\begin{tabular}{cccc}
\hline$\cdot$ & $(+)$ & $(0)$ & $(-)$ \\
\hline$(+)$ & $(+)$ & $(0)$ & $(-)$ \\
$(0)$ & $(0)$ & $(0)$ & $(0)$ \\
$(-)$ & $(-)$ & $(0)$ & $(+)$ \\
\hline
\end{tabular}

The easiest way to solve the trend model is to create all possible triplets for each variable and then check which of these triplets meet the equation using the qualitative sum and product and thus which of these three are the scenarios. Since only qualitative values are being employed determining all the possible triplets is a simple combinatorial task.

Since all the elements of a triplet can be replaced by the final number of qualitative values, the set $M$ contains only the final number of scenarios. Thus, when solving the trend model, we always obtain the final set of solutions.

For example, let us consider variables $X_{1}$ and $X_{2}$. To simplify the description of the principle of trend reconstruction, the first and second derivatives of $X_{1}$ and $X_{2}$ are not considered. The set $\mathrm{S}_{\mathrm{M}}$ of solutions consists of two scenarios, see Table 6.

For each scenario of Table 6 using the operations of qualitative sum and product, (see (Dohnal and Doubravsky, 2015)), the equations relevant to these scenarios can be identified.

Both scenarios have a common first equation, see Table 7. Thus, the formula $X+Y=0$ is a reconstructed linear model $\mathrm{M}_{\mathrm{SL}}$.

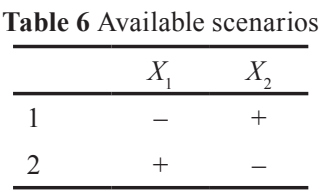

Table 7 Equations of the first scenario, see Table 6

\begin{tabular}{llc}
\hline & $\begin{array}{c}\text { The equation of the first } \\
\text { scenario, see Table } 6\end{array}$ & $\begin{array}{c}\text { The equation of the second } \\
\text { scenarios, see Table } 6\end{array}$ \\
\hline 1 & $(+) X_{1}+(+) X_{2}=(0)$ & $(+) X_{1}+(+) X_{2}=(0)$ \\
2 & $(+) X_{1}+(0) X_{2}=(-)$ & $(+) X_{1}+(0) X_{2}=(+)$ \\
3 & $(0) X_{1}+(+) X_{2}=(+)$ & $(0) X_{1}+(+) X_{2}=(-)$
\end{tabular}




\section{Case study}

The qualitative model, given in (Doskočil and Doubrav sky, 2017;Sakellaropoulos and Chassiakos, 2004; Tran et al., 2015) has the following variables:

- $P P C$-Direct personnel costs

- $P M C$-Direct material costs

- $P S C$-Direct subcontract costs

- $I P C$-Indirect personnel costs

- $I O C$-Indirect operating costs

- $T F C$-Taxes and fees costs

- PD-Project duration.

The following equation-less trend model M, see Table 8, is based on pairwise trend relations Eq. (4).

There is the set of 45 scenarios (see Table 8 ) if the equation less model, is used to generate them and all variables are positive, which means that all triplets have the following general form (+, evaluate, evaluate). For example, any project duration $P D$ is always positive by its very nature.

It is relatively easy to generate a list of all the possible transitions between the 45 scenarios, see Table 9, using Table 3.

There are 304 transitions in the transitional graph $\mathrm{G}_{\mathrm{M}}$, see Fig. 3. Its nodes are the scenarios $\mathrm{S}$, see Table 9, and oriented arcs are the transitions between the scenarios $\mathrm{S}$.

Because the pairwise relationships, see Table 8 , are based on experiences and observations of project team members, these pairwise relations need not describe all relations of monitored variables.

From scenarios $\mathrm{S}_{\mathrm{ML}}$, see Table 9, the following trend model $\mathrm{M}_{\mathrm{SL}}$ (a set of 7 linear equations) is reconstructed.

For example, the row No. 5 of the model $\mathrm{M}_{\mathrm{SL}}$, see Table 10, expresses the following linear equation Eq. (15):

$$
\begin{aligned}
& I O C+\mathrm{D} I O C+\mathrm{DD} I O C-T F C-\mathrm{D} T F C-\mathrm{DD} T F C \\
& -P S C+\mathrm{D} P S C=0 .
\end{aligned}
$$

\begin{tabular}{|c|c|c|c|c|c|c|c|}
\hline & $P D$ & $P P C$ & $P M C$ & $I P C$ & $I O C$ & $T F C$ & PSC \\
\hline 1 & +++ & +-+ & +++ & +++ & +++ & +++ & +-- \\
\hline 2 & +++ & +-+ & ++0 & +++ & +++ & +++ & +-- \\
\hline 3 & +++ & +-+ & ++- & +++ & +++ & +++ & +-+ \\
\hline 4 & +++ & +-+ & ++- & +++ & +++ & +++ & +-0 \\
\hline 5 & +++ & +-+ & ++- & +++ & +++ & +++ & +-- \\
\hline 6 & +++ & +-0 & +++ & +++ & +++ & +++ & +-- \\
\hline 7 & +++ & +-0 & ++0 & +++ & +++ & +++ & +-- \\
\hline 8 & +++ & +-0 & ++- & +++ & +++ & +++ & +-+ \\
\hline 9 & +++ & +-0 & ++- & +++ & +++ & +++ & +-0 \\
\hline 10 & +++ & +-0 & ++- & +++ & +++ & +++ & +-- \\
\hline 11 & +++ & +-- & +++ & +++ & +++ & +++ & +-- \\
\hline 12 & +++ & +-- & ++0 & +++ & +++ & +++ & +-- \\
\hline 13 & +++ & +-- & ++- & +++ & +++ & +++ & +-+ \\
\hline 14 & +++ & +-- & ++- & +++ & +++ & +++ & +-0 \\
\hline 15 & +++ & +-- & ++- & +++ & +++ & +++ & +-- \\
\hline 16 & ++0 & +-+ & ++- & ++0 & ++0 & ++0 & +-+ \\
\hline 17 & ++0 & +-+ & ++- & ++0 & ++0 & ++0 & +-0 \\
\hline 18 & ++0 & +-+ & ++- & ++0 & ++0 & ++0 & +-- \\
\hline 19 & ++- & +-+ & ++- & ++- & ++- & ++- & +-+ \\
\hline 20 & ++- & +-+ & ++- & ++- & ++- & ++- & +-0 \\
\hline 21 & ++- & +-+ & ++- & ++- & ++- & ++- & +-- \\
\hline 22 & $+0+$ & $+0-$ & $+0+$ & $+0+$ & $+0+$ & $+0+$ & $+0-$ \\
\hline 23 & +00 & +00 & +00 & +00 & +00 & +00 & +00 \\
\hline 24 & $+0-$ & $+0+$ & $+0-$ & $+0-$ & $+0-$ & $+0-$ & $+0+$ \\
\hline 25 & +-+ & +++ & +-+ & +-+ & +-+ & +-+ & ++- \\
\hline 26 & +-+ & +++ & +-0 & +-+ & +-+ & +-+ & ++- \\
\hline 27 & +-+ & +++ & +-- & +-+ & +-+ & +-+ & +++ \\
\hline 28 & +-+ & +++ & +-- & +-+ & +-+ & +-+ & ++0 \\
\hline 29 & +-+ & +++ & +-- & +-+ & +-+ & +-+ & ++- \\
\hline 30 & +-+ & ++0 & +-+ & +-+ & +-+ & +-+ & ++- \\
\hline 31 & +-+ & ++0 & +-0 & +-+ & +-+ & +-+ & ++- \\
\hline 32 & +-+ & ++0 & +-- & +-+ & +-+ & +-+ & +++ \\
\hline 33 & +-+ & ++0 & +-- & +-+ & +-+ & +-+ & ++0 \\
\hline 34 & +-+ & ++0 & +-- & +-+ & +-+ & +-+ & ++- \\
\hline 35 & +-+ & ++- & +-+ & +-+ & +-+ & +-+ & ++- \\
\hline 36 & +-+ & ++- & +-0 & +-+ & +-+ & +-+ & ++- \\
\hline 37 & +-+ & ++- & +-- & +-+ & +-+ & +-+ & +++ \\
\hline 38 & +-+ & ++- & +-- & +-+ & +-+ & +-+ & ++0 \\
\hline 39 & +-+ & ++- & +-- & +-+ & +-+ & +-+ & ++- \\
\hline 40 & +-0 & +++ & +-- & +-0 & +-0 & +-0 & +++ \\
\hline 41 & +-0 & +++ & +-- & +-0 & +-0 & +-0 & ++0 \\
\hline 42 & +-0 & +++ & +-- & +-0 & +-0 & +-0 & ++- \\
\hline 43 & +-- & +++ & +-- & +-- & +-- & +-- & +++ \\
\hline 44 & +-- & +++ & +-- & +-- & +-- & +-- & ++0 \\
\hline 45 & +-- & +++ & +-- & +-- & +-- & +-- & ++- \\
\hline
\end{tabular}

Table 9 Scenarios of the trend model in Table 8

\begin{tabular}{cccc}
\multicolumn{4}{c}{ Table 8 Equation-less trend model } \\
\hline & $X$ & $Y$ & Shape, see Fig. 1 \\
\hline 1 & $P D$ & $P P C$ & 24 \\
2 & $P D$ & $P M C$ & 23 \\
3 & $P D$ & $I P C$ & 22 \\
4 & $P D$ & $I O C$ & 22 \\
5 & $P D$ & $T F C$ & 22 \\
6 & $P M C$ & $P S C$ & 25 \\
7 & $P P C$ & $I P C$ & 24 \\
8 & $P P C$ & $I O C$ & 24 \\
9 & $P P C$ & $T F C$ & 24 \\
\hline & & &
\end{tabular}




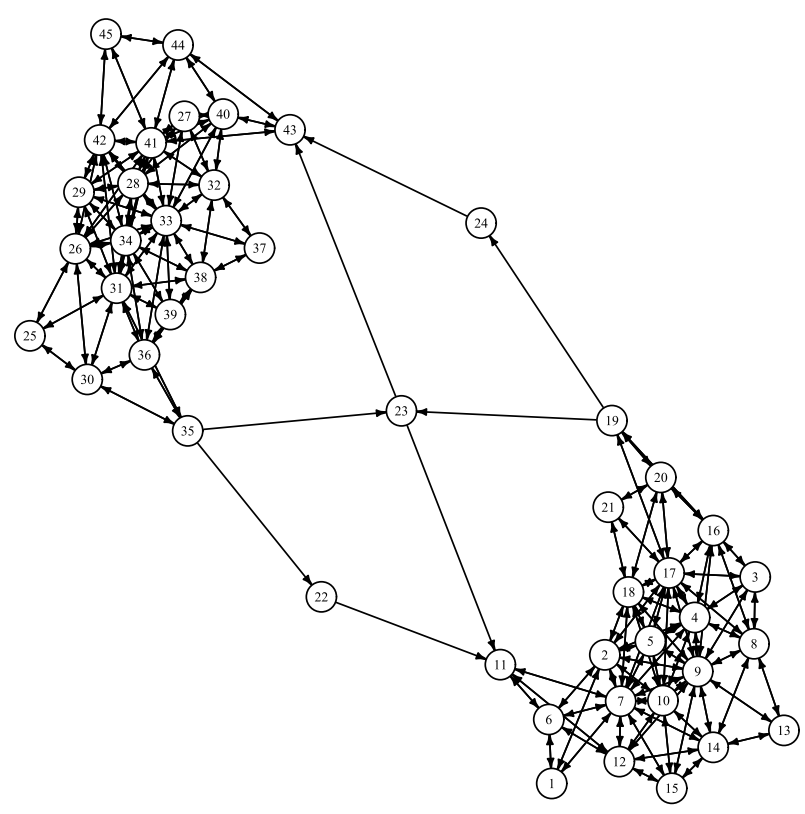

Fig. 3 Transitional graph $G_{M}$ based on the set of scenarios in Table 9

Table 10 Set of 7 linear equations

\begin{tabular}{ccccccccc}
\hline & $P D$ & $P P C$ & $P M C$ & $I P C$ & $I O C$ & TFC & $P S C$ & Right side \\
\hline 1 & +++ & -+0 & --0 & --- & --- & --- & -+0 & 0 \\
2 & 000 & ++0 & -+0 & -+0 & -+0 & -+0 & --0 & 0 \\
3 & 000 & 000 & ++0 & --0 & --0 & --0 & -+0 & 0 \\
4 & 000 & 000 & 000 & +++ & --- & --- & -+0 & 0 \\
5 & 000 & 000 & 000 & 000 & +++ & --- & -+0 & 0 \\
6 & 000 & 000 & 000 & 000 & 000 & $0+0$ & $0+0$ & 0 \\
7 & +00 & +00 & +00 & +00 & +00 & +00 & +00 & + \\
\hline
\end{tabular}

The set of 7 linear differential equations, Table 10, is the trend model. The trend analysis of the reconstructed model $\mathrm{M}_{\mathrm{SL}}$ is the set $\mathrm{S}_{\mathrm{ML}}$ of 243 scenarios. A sample of a part of these scenarios is listed in Table 11.

The set $\mathrm{S}_{\mathrm{ML}}$ (Table 11) contains 198 additional scenarios, Nos. 46-243.

The sets of scenarios $\mathrm{S}_{\mathrm{ML}}$ are not the only trend results. It is very easy to generate transitions between the set of these scenarios by respecting the transitions in Table 3 . There are 4704 transitions in the transitional graph $\mathrm{G}_{\mathrm{ML}}$, see Fig. 4 .

The dark nodes represent the transitional graph $\mathrm{G}_{\mathrm{M}}$ based on the scenarios in Table 9. It is evident that the transitional graph is the sub-graph of the transitional graph $G_{M}$, see Fig. 4. Its nodes are the scenarios, $S$ (Table 11) and the oriented arcs are the transitions between the scenarios, $\mathrm{S}$.

Fig. 4 shows all the possible oriented paths. Any path is a trend description of a forecast or a history. It means that the transitional graph represents all possible future/past behaviors of the equation-less trend model M, see Table 8 .
Table 11 Scenarios $\mathrm{S}_{\mathrm{ML}}$ of the trend model $\mathrm{M}_{\mathrm{SL}}$, see Table 10

\begin{tabular}{|c|c|c|c|c|c|c|c|}
\hline & $P D$ & $P P C$ & $P M C$ & $I P C$ & $I O C$ & $T F C$ & PSC \\
\hline 1 & +++ & +-+ & +++ & +++ & +++ & +++ & +-- \\
\hline 2 & +++ & +-+ & ++0 & +++ & +++ & +++ & +-- \\
\hline 3 & +++ & +-+ & ++- & +++ & +++ & +++ & +-+ \\
\hline$\ldots$ & $\ldots$ & $\ldots$ & $\ldots$ & $\ldots$ & $\ldots$ & $\ldots$ & $\ldots$ \\
\hline 14 & +++ & +-- & ++- & +++ & +++ & +++ & +-0 \\
\hline 15 & +++ & +-- & ++- & +++ & +++ & +++ & +-- \\
\hline 16 & ++0 & +-+ & ++- & ++0 & ++0 & ++0 & +-+ \\
\hline 17 & ++0 & +-+ & ++- & ++0 & ++0 & ++0 & +-0 \\
\hline 18 & ++0 & +-+ & ++- & ++0 & ++0 & ++0 & +-- \\
\hline 19 & ++- & +-+ & ++- & ++- & ++- & ++- & +-+ \\
\hline$\ldots$ & $\ldots$ & $\ldots$ & $\ldots$ & $\ldots$ & $\ldots$ & $\ldots$ & $\ldots$ \\
\hline 43 & +-- & +++ & +-- & +-- & +-- & +-- & +++ \\
\hline 44 & +-- & +++ & +-- & +-- & +-- & +-- & ++0 \\
\hline 45 & +-- & +++ & +-- & +-- & +-- & +-- & ++- \\
\hline 46 & +00 & +00 & +00 & +00 & +00 & +00 & $+0+$ \\
\hline 47 & +00 & +00 & +00 & +00 & +00 & +00 & $+0-$ \\
\hline 48 & +00 & +00 & $+0+$ & +00 & +00 & +00 & +00 \\
\hline 49 & +00 & +00 & $+0+$ & +00 & +00 & +00 & $+0+$ \\
\hline 50 & +00 & +00 & $+0+$ & +00 & +00 & +00 & $+0-$ \\
\hline 51 & +00 & +00 & $+0-$ & +00 & +00 & +00 & +00 \\
\hline 52 & +00 & +00 & $+0-$ & +00 & +00 & +00 & $+0+$ \\
\hline$\cdots$ & $\ldots$ & $\ldots$ & $\ldots$ & $\ldots$ & $\ldots$ & $\ldots$ & $\ldots$ \\
\hline 112 & $+0-$ & $+0+$ & $+0+$ & $+0-$ & $+0-$ & $+0-$ & $+0-$ \\
\hline 113 & $+0-$ & $+0+$ & $+0-$ & $+0-$ & $+0-$ & $+0-$ & +00 \\
\hline 114 & $+0-$ & $+0+$ & $+0-$ & $+0-$ & $+0-$ & $+0-$ & $+0-$ \\
\hline$\cdots$ & $\ldots$ & $\ldots$ & $\ldots$ & $\ldots$ & $\ldots$ & $\ldots$ & $\ldots$ \\
\hline 227 & +-- & ++0 & +-- & +-- & +-- & +-- & +++ \\
\hline 228 & +-- & ++0 & +-- & +-- & +-- & +-- & ++- \\
\hline 229 & +-- & +++ & +-0 & +-- & +-- & +-- & ++0 \\
\hline 230 & +-- & +++ & +-0 & +-- & +-- & +-- & +++ \\
\hline 231 & +-- & +++ & +-0 & +-- & +-- & +-- & ++- \\
\hline 232 & +-- & +++ & +-+ & +-- & +-- & +-- & ++0 \\
\hline 233 & +-- & +++ & +-+ & +-- & +-- & +-- & +++ \\
\hline 234 & +-- & +++ & +-+ & +-- & +-- & +-- & ++- \\
\hline 235 & +-- & ++- & +-0 & +-- & +-- & +-- & ++0 \\
\hline 236 & +-- & ++- & +-0 & +-- & +-- & +-- & +++ \\
\hline 237 & +-- & ++- & +-0 & +-- & +-- & +-- & ++- \\
\hline 238 & +-- & ++- & +-+ & +-- & +-- & +-- & ++0 \\
\hline 239 & +-- & ++- & +-+ & +-- & +-- & +-- & +++ \\
\hline 240 & +-- & ++- & +-+ & +-- & +-- & +-- & ++- \\
\hline 241 & +-- & ++- & +-- & +-- & +-- & +-- & ++0 \\
\hline 242 & +-- & ++- & +-- & +-- & +-- & +-- & +++ \\
\hline 243 & +-- & ++- & +-- & +-- & +-- & +-- & ++- \\
\hline
\end{tabular}

Therefore, any forecast is identical to a choice of a path through the transitional graph $\mathrm{G}_{\mathrm{ML}}$. 


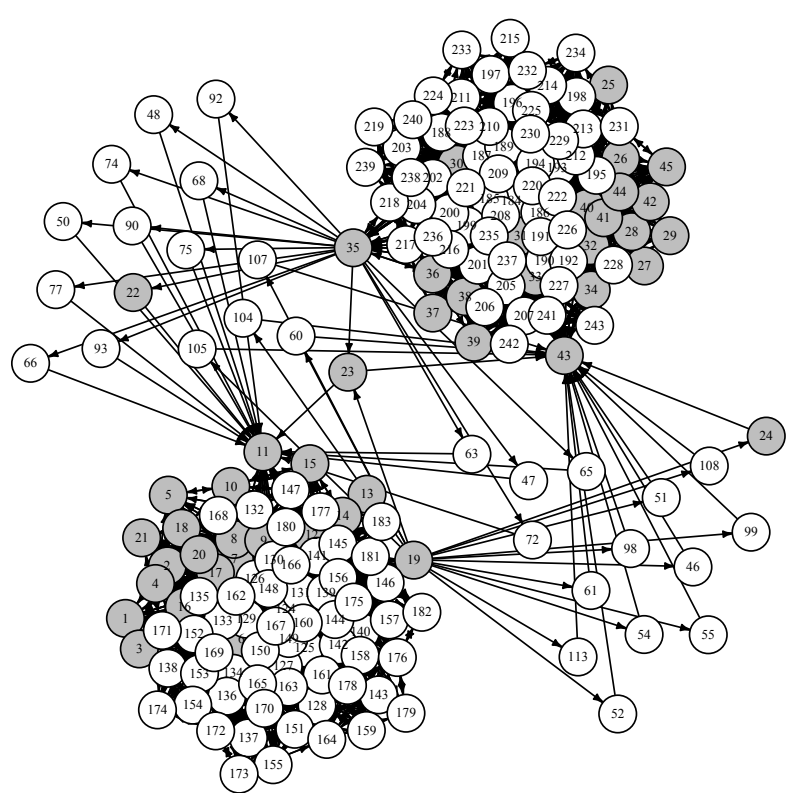

Fig. 4 Transitional graph $\mathrm{G}_{\mathrm{ML}}$ based on the set of scenarios in Table 11

\section{Results and discussion}

The case study analysed in this paper (Table 8) will be used to demonstrate interpretations of the relevant trend results. This explanation does not require a complete understanding of the theory outlined above and is based only on concepts of the first and second derivatives.

The linear reconstructed model $\mathrm{M}_{\mathrm{SL}}$ allows the identification of all additional interrelationships between the monitored variables.

Let scenario 19 be the current situation, see all nodes in Fig. 4. For example, it is possible to move from node 19 to node 113 and to node 43 and to the node 227 or from node 19 to node 52 and to node 43 and to the node 227 . Let us study the sequence $19 \rightarrow 113 \rightarrow 43 \rightarrow 227$ represented by four scenarios 19, 113, 43 and 227 in Table 11.

This sequence is described by Table 12 .

Then, Fig. 5 shows the trend function $P P C(t)$.

The trend graph of the sequence $19 \rightarrow 52 \rightarrow 43 \rightarrow 227$ represented by four scenarios 19, 52, 43 and 227, (Table 11 or Table 12).

Table 12 Studied scenarios

\begin{tabular}{llllllll}
\hline No. & $P D$ & $P P C$ & $P M C$ & $I P C$ & IOC & TFC & $P S C$ \\
\hline 19 & ++- & +-+ & ++- & ++- & ++- & ++- & +-+ \\
43 & +-- & +++ & +-- & +-- & +-- & +-- & +++ \\
52 & +00 & +00 & $+0-$ & +00 & +00 & +00 & $+0+$ \\
113 & $+0-$ & $+0+$ & $+0-$ & $+0-$ & $+0-$ & $+0-$ & +00 \\
227 & +-- & ++0 & +-- & +-- & +-- & +-- & +++ \\
\hline
\end{tabular}

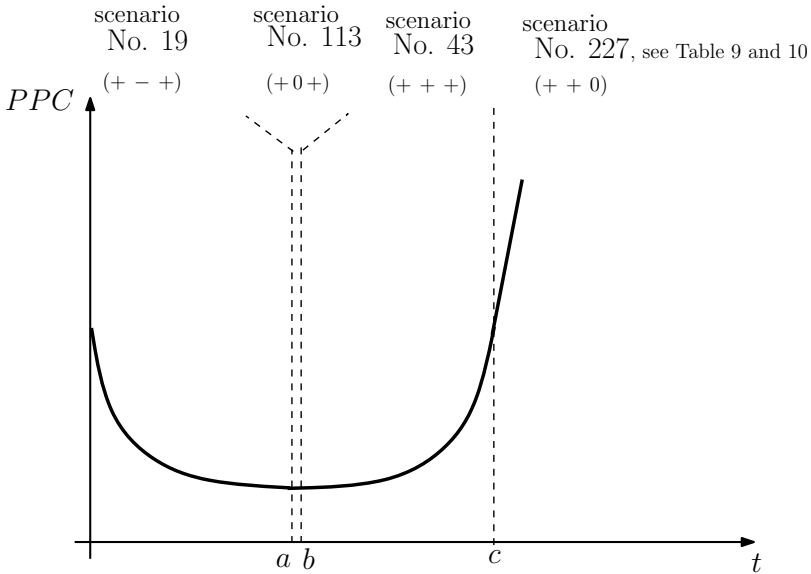

Fig. 5 Trend description of the function $P P C(t)$

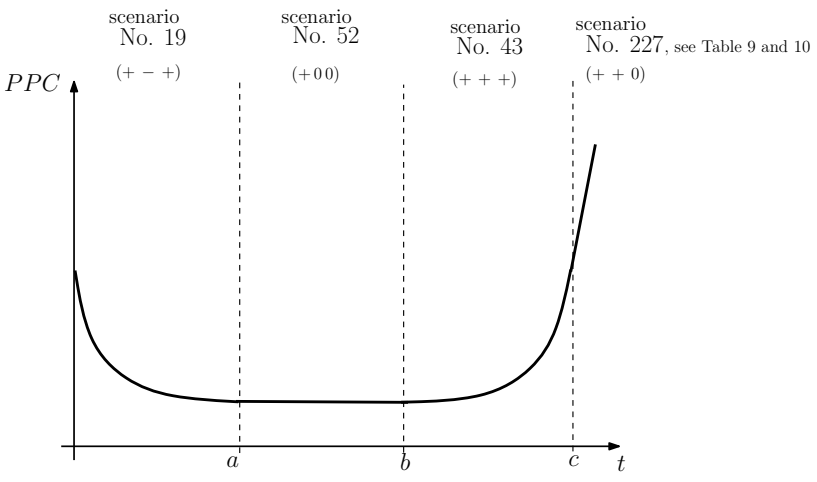

Fig. 6 Trend description of the function $P P C(t)$

Fig. 5 and Fig. 6 do not represent a conventional graph but are trend graphs. Thus the only restrictions are the following inequalities:

$0<a<b<c$.

The numerical values of intervals, e.g. $(a-c)$ are irrelevant. Thus, Fig. 5 and Fig. 6 represent the future behaviour of the variable $P P C$. Similarly, the trend graph can be determined for the other variables.

The results presented above and the approach described can be used in project management, particularly in the process of time-cost analysis. This is the initialization and project planning phase from the point of view of the project life cycle. Knowledge of the trend functions of monitored variables presented above allows project managers to better understand the relationships between these monitored variables, so that they can obtain a more accurate idea of how variable(s) can be affected by changing other variable(s). For example, the variable $P P C$ decreases when the variables $P D, P M C, I P C, I O C, T F C$ increase, but the 
growth rate slows, and the variable PSC decreases but the rate of decline slows, see Table 12 . However, if the variable $P P C$ is in state 227 it is not possible to directly get the variable $P P C$ to state 19 (there is no transition between the nodes 227 and 19, see Fig. 4).

Concrete numerical inputs about time durations and costs of project activities are not permitted in this phase. According the traditional approaches based on parametric linear programming or special algorithms (e.g., Kelley's algorithm, Ford-Fulkerson's algorithm), the advantage of the approach proposed here is the fact that no numeric values are required. Also, the approach to solution, based on the experiences of project managers and common sense, is more user friendly compared to traditional and special algorithms. These algorithms are relatively complicated and computationally lengthy. The model provides project managers with basic information and knowledge about the behaviour of the system (project). This knowledge can help them by providing a time-cost analysis of the project. They also may not always provide accurate and meaningful results, because they are based on the application of mathematical and statistical means. It is also possible to experiment with the model in the form of simulations at the project execution phase. This provides project managers with a tool to support decision-making and effective project management.

The main advantage of the proposed trend reconstruction method is:

- No quantitative/numerical, fuzzy sets etc. values of constants are needed

- A complete list of all possible dynamic behaviours is obtained.

- The results are very easy to understand

- Other variables can easily be integrated.

The most important disadvantage of trend reconstruction is its linearity. A nonlinear trend reconstruction is currently a non-achievable goal. However, let us suppose that a user knows that it makes sense to take into consideration a certain nonlinear element. This common sense conclusion is based on their knowledge of the theoretical background of the project management problem being considered using deep and/or shallow knowledge items.

\section{Conclusion}

Trend analysis and consequently trend modelling offers a partial solution. The trend model is information non-intensive as it is based merely on trends and can easily incorporate various vague heuristics generated by experts.

Trend reconstruction is the reverse processes to the trend analysis. General algorithms of the nonlinear trend reconstruction do not exist. However, the reconstruction of a set of linear differential equations based on a set of scenarios covers a relatively broad spectrum of tasks related to poorly known project management problems. In other words, if the reconstructed linear model is not accepted by project management experts then no applicable model can be developed.

Complex tasks of project management problems are related mainly to soft sciences, e.g. psychology, sociology or macroeconomics. They are usually unique, partially subjective, inconsistent, vague and multidimensional. Oversimplified and/or highly specific quantitative models are often obtained if traditional numerical analysis is employed. The key reason for this is a severe shortage of information. Therefore, models of project management in the form of linear differential equations can be more easily integrated with conventional decision making and forecasting algorithms. This integration will be the next step towards real-life studies.

Several problems of qualitative modelling remain unsolved and therefore the results of qualitative approach of some models can be problematic. For example, it is known that ineradicably spurious behaviours exist. Qualitative simulators have to include them in their scenario sets (Say and Akın, 2003). Moreover, some interpretation tasks are not fully understood. (Šuc et al., 2004). However, the above-mentioned approach is fully applicable. Any further steps in developing qualitative modelling will further enhance the accuracy of the results.

\section{Acknowledgment}

This paper was supported by a grant from the Czech Science Foundation. The Projects: The Development of new methods of solving dynamic models of corporate processes management, Registration No. 16-03796S and Modelling and Simulation of Sustainable Investment Decision-making, Registration No. 17-23448S. 


\section{References}

Bosurgi, G., Pellegrino, O., Sollazzo, G. (2017) "Project Duration Evaluated Using Affine Arithmetic", Periodica Polytechnica Civil Engineering, 61(3), pp. 412-420.

https://doi.org/10.3311/PPci.8972

Bredeweg, B., Liem, J., Nicolaou, C. (2016) "Assessing LearnerConstructed Conceptual Models and Simulations of Dynamic Systems", In: Verbert, K., Sharples, M., Klobučar, T. (eds.) Adaptive and Adaptable Learning, Lecture Notes in Computer Science, Springer International Publishing, Cham, Switzerland, pp. 357-362. https://doi.org/10.1007/978-3-319-45153-4_27

de Villiers, R., Woodside, A. G., Marshall, R. (2016) "Making tough decisions competently: Assessing the value of product portfolio planning methods, devil's advocacy, group discussion, weighting priorities, and evidenced-based information", Journal of Business Research, 69(8), pp. 2849-2862.

https://doi.org/10.1016/j.jbusres.2015.12.054

Dincbas, M., Simonis, H., Van Hentenryck, P. (1990) "Solving large combinatorial problems in logic programming", The Journal of Logic Programming, Special Issue: Logic Programming Applications, 8(1-2), pp. 75-93.

https://doi.org/10.1016/0743-1066(90)90052-7

Dohnal, M. (1991) "A methodology for common-sense model development", Computers in Industry, 16(2), pp. 141-158. https://doi.org/10.1016/0166-3615(91)90086-O

Dohnal, M., Doubravsky, K. (2015) "Qualitative Upper and Lower Approximations of Complex Nonlinear Chaotic and Nonchaotic Models", International Journal of Bifurcation and Chaos, 25(13), article ID: 1550173. https://doi.org/10.1142/S0218127415501734

Dohnal, M., Doubravsky, K. (2016) "Equationless and equation-based trend models of prohibitively complex technological and related forecasts", Technological Forecasting and Social Change, 111, pp. 297-304.

https://doi.org/10.1016/j.techfore.2016.07.031

Doskočil, R., Doubravský, K. (2017) "Qualitative Evaluation of Knowledge Based Model of Project Time-Cost as Decision Making Support", Economic Computation and Economic Cybernetics Studies and Research, 51(1), pp. 263-280. [online] Available at: ftp://www.ipe.ro/RePEc/cys/ecocyb_pdf/ecocyb1_2017p263-280. pdf [Accessed: 08 October 2018]

Doubravsky, K., Dohnal, M. (2018) "Qualitative equationless macroeconomic models as generators of all possible forecasts based on three trend values - Increasing, constant, decreasing", Structural Change and Economic Dynamics, 45, pp. 30-36. https://doi.org/10.1016/j.strueco.2018.01.001

Hajdu, M. (2013) "Two Scheduling Models, One Project: Are Models Applicable in Case of Real Projects?", Procedia - Social and Behavioral Sciences, 74, pp. 165-174. https://doi.org/10.1016/j.sbspro.2013.03.023

Harrington, J., Salibián-Barrera, M. (2010) "Finding approximate solutions to combinatorial problems with very large data sets using BIRCH", Computational Statistics \& Data Analysis, 54(3), pp. 655-667. https://doi.org/10.1016/j.csda.2008.08.001
Joslin, R., Müller, R. (2015) "Relationships between a project management methodology and project success in different project governance contexts", International Journal of Project Management, 33(6), pp. 1377-1392.

https://doi.org/10.1016/j.ijproman.2015.03.005

Jugdev, K., Müller, R. (2005) "A Retrospective Look at Our Evolving Understanding of Project Success", Project Management Journal, 36(4), pp. 19-31. [online] Available at: http://auspace.athabascau. ca/handle/2149/277 [Accessed: 15 September 2015]

Kelley Jr., J. E. (1961) "Critical-Path Planning and Scheduling: Mathematical Basis", Operations Research, 9(3), pp. 296-320. https://doi.org/10.1287/opre.9.3.296

Kelley Jr., J. E., Walker, M. R. (1959) "Critical-Path Planning and Scheduling", In: Eastern Joint IRE-AIEE-ACM Computer Conference, IRE-AIEE-ACM '59 (Eastern), Boston, Massachusetts, USA, pp. 160-173. https://doi.org/10.1145/1460299.1460318

Klafszky, E., Hajdu, M. (1993) "An Algorithm to Solve the Cost Optimization Problem through an Activity on Arrow Type Network (CPM/Cost Problem)", Periodica Polytechnica Architecture, 37(1-4), pp. 27-40. [online] Available at: https://pp.bme.hu/ar/article/view/2209 [Accessed: 19 December 2018]

Koltai, T., Tamássy, A. (1997) "The Design Process of an Activity Based Cost (ABC) System at a Chest Freezer Assembly Plant: A Case Study", Periodica Polytechnica Social and Management Sciences, 5(1), pp. 49-62. [online] Available at: https://pp.bme.hu/so/article/ view/6501 [Accessed: 19 December 2018]

Mályusz, L., Hajdu, M. (2009) "How would you like it: cheaper or shorter", Organization, Technology \& Management in Construction: An International Journal, 1(2), pp. 59-63. [online] Available at: https://hrcak.srce.hr/index.php?show=clanak\&id_clanak_jezik=97372 [Accessed: 19 December 2018]

Orrell, D., Fernandez, E. (2010) "Using Predictive Mathematical Models to Optimise the Scheduling of Anti-Cancer Drugs", Innovations in Pharmaceutical Technology, (33), pp. 59-62. [online] Available at: http://www.iptonline.com/articles/public/Physiomics\%20article\%20NP.pdf [Accessed: 19 December 2018]

Orrell, D., McSharry, P. (2009) "System economics: Overcoming the pitfalls of forecasting models via a multidisciplinary approach", International Journal of Forecasting, Special section: Decision making and planning under low levels of predictability, 25(4), pp. 734-743.

https://doi.org/10.1016/j.ijforecast.2009.05.002

Sakellaropoulos, S., Chassiakos, A. P. (2004) "Project time-cost analysis under generalised precedence relations", Advances in Engineering Software, Engineering Computational Technology, 35(10-11), pp. $715-724$. https://doi.org/10.1016/j.advengsoft.2004.03.017

Say, A. C. C., Akın, H. L. (2003) "Sound and complete qualitative simulation is impossible", Artificial Intelligence, 149(2), pp. 251-266. https://doi.org/10.1016/S0004-3702(03)00077-8

Serrador, P., Pinto, J. K. (2015) "Does Agile work? - A quantitative analysis of agile project success", International Journal of Project Management, 33(5), pp. 1040-1051.

https://doi.org/10.1016/j.ijproman.2015.01.006 
Singhi, N. M., Shriniwas, I., Antony, T. A. (1996) "Combinatorial Techniques and Objects in Computer Science: Fault-tolerance and Other Interesting Applications", European Journal of Combinatorics, 17(2-3), pp. 97-111. https://doi.org/10.1006/eujc.1996.0009

Song, Y., Yang, L., Li, G., Gao, T. (2015) "Knowledge Sharing and dynamic capability: A system dynamic model for innovation projects organization", In: 10th International Forum on Knowledge Asset Dynamics: Culture, Innovation and Entrepreneurship: Connecting the Knowledge Dots, Bari, Italy, pp. 209-221.

Šuc, D., Vladušič, D., Bratko, I. (2004) "Qualitatively faithful quantitative prediction", Artificial Intelligence, 158(2), pp. 189-214. https://doi.org/10.1016/j.artint.2004.05.002

Šviráková, E. (2014) "System Dynamics Methodology: Application in Project Management Education", In: Efficiency and Responsibility in Education, Czech University Life Sciences Prague, Prague, Czech Republic, pp. 813-822. [online] Available at: http://m.publikace.k.utb.cz/handle/10563/1004238 [Accessed: 10 October 2018]

Tran, D.-H., Cheng, M.-Y., Cao, M.-T. (2015) "Hybrid multiple objective artificial bee colony with differential evolution for the timecost-quality tradeoff problem", Knowledge-Based Systems, 74, pp. $176-186$.

https://doi.org/10.1016/j.knosys.2014.11.018
Vanhoucke, M. (2013) "Project Management with Dynamic Scheduling: Baseline Scheduling, Risk Analysis and Project Control", Springer-Verlag, Berlin, Heidelberg, Germany. https://doi.org/10.1007/978-3-642-40438-2

Vicha, T., Dohnal, M. (2008) "Qualitative identification of chaotic systems behaviours", Chaos, Solitons \& Fractals, 38(1), pp. 70-78. https://doi.org/10.1016/j.chaos.2008.01.027

Wu, P., Zhang, Y., Fang, F. (2007) "Application of system dynamic model in software project management", In: Conference on Systems Science, Management Science and System Dynamics: Sustainable Development and Complex Systems, Shanghai, China, pp. 2321-2326.

Yan, X., Zhou, Y., Wen, Y., Chai, X. (2013) "Qualitative and Quantitative Integrated Modeling for Stochastic Simulation and Optimization", Journal of Applied Mathematics, article number: 831273. https://doi.org/10.1155/2013/831273 